\title{
The Challenging Diagnosis of Non-Community-Acquired Pneumonia in Non-Mechanically Ventilated Subjects: Value of Microbiological Investigation
}

\author{
Jonathan Messika MD, Annabelle Stoclin MD, Eric Bouvard MD, Jean-Pierre Fulgencio MD, \\ Christophe Ridel MD, Ioan-Paul Muresan MD, Jean-Jacques Boffa MD PhD, \\ Claude Bachmeyer MD, Michel Denis MD, Valérie Gounant MD, Adoracion Esteso MD, \\ Valeria Loi MD, Charlotte Verdet PharmD PhD, Hélène Prigent MD PhD, Antoine Parrot MD, \\ and Muriel Fartoukh MD PhD
}

\begin{abstract}
BACKGROUND: Early recognition and an attempt at obtaining microbiological documentation are recommended in patients with non-community-acquired pneumonia (NCAP), whether hospitalacquired (HAP) or health care-associated (HCAP). We aimed to characterize the clinical features and microbial etiologies of NCAP to assess the impact of microbiological investigation on their management. METHODS: This was a prospective 1-y study in a university hospital with 141 non-mechanically ventilated subjects suspected of having HAP $(n=110)$ or HCAP $(n=31)$. RESULTS: Clinical criteria alone poorly identified pneumonia (misdiagnosis in $50 \%$ of cases). Microbiological confirmation was achievable in 80 subjects (57\%). Among 79 microorganisms isolated, 28 were multidrug-resistant aerobic Gram-negative bacilli and group III Enterobacteriaceae and 6 were methicillin-resistant Staphylococcus aureus. Multidrug-resistant aerobic Gramnegative bacilli accounted for one third of the microorganisms in early-onset HAP and for $50 \%$ in late-onset HAP. Methicillin-resistant $S$. aureus was most often recovered from subjects with HCAP. Inappropriate empirical antibiotics were administered to $36 \%$ of subjects with confirmed pneumonia. Forty subjects were admitted to the ICU, $13(33 \%)$ of whom died. Overall, 39 subjects $(28 \%)$ died in the hospital. CONCLUSIONS: Integrating the microbiological investigation in the complex clinical diagnostic workup of patients suspected of having NCAP is mandatory. Respiratory tract specimens should be obtained whenever possible for appropriate management. Key words: hospitalacquired pneumonia; diagnosis; multidrug-resistant microorganisms; antibiotics; nosocomial infection. [Respir Care 2016;61(2):225-234. (C) 2016 Daedalus Enterprises]
\end{abstract}

\section{Introduction}

Non-community-acquired pneumonia (NCAP) has been recently differentiated into health care-associated pneumo-

\footnotetext{
Dr Messika is affiliated with the Service de Réanimation Médico-Chirurgicale, Hôpital Tenon, Assistance Publique-Hôpitaux de Paris (AP-HP), Paris, France, Service de Réanimation Médico-Chirurgicale, Hôpital Louis Mourier, AP-HP, Colombes, France, Univ Paris Diderot, Sorbonne Paris Cité, IAME, UMRS 1137, Paris, France, and INSERM, IAME, U1137, Paris, France. Drs Stoclin, Fulgencio, and Parrot are affiliated with the Service de Réanimation Médico-Chirurgicale, Hôpital Tenon, AP-HP, Paris, France. Drs Bouvard and Bachmeyer are affiliated with the Service de Médecine Interne, Hôpital Tenon, AP-HP, Paris, France. Dr Ridel is
}

nia (HCAP), hospital-acquired pneumonia (HAP) developing $48 \mathrm{~h}$ after hospitalization, and ventilator-associated pneumonia developing during mechanical ventilation. ${ }^{1,2}$

\footnotetext{
affiliated with the Service des Urgences Néphrologiques et Transplantation Rénale, Hôpital Tenon, AP-HP, Paris, France. Dr Muresan is affiliated with the Service de Neurologie, Hôpital Tenon, AP-HP, Paris, France. Dr Boffa is affiliated with the Service de Néphrologie et Dialyse, Hôpital Tenon, AP-HP, Paris, France and Sorbonne Universités, UPMC Univ Paris 06, Paris, France. Dr Denis is affiliated with the Service de Maladies Infectieuses et Tropicales, Hôpital Tenon, AP-HP, Paris, France. Dr Gounant is affiliated with the Service de Pneumologie, Hôpital Tenon, AP-HP, Paris, France. Dr Esteso is affiliated with the Service d'Oncologie Médicale, Hôpital Tenon, AP-HP, Paris, France. Dr Loi is affiliated with the Service de Chirurgie Digestive, AP-HP, Hôpital Tenon, Paris, France.
} 
Several clinical investigations have confirmed the frequency of health care-associated infections, of which the most common types are pneumonia, ${ }^{3}$ and have suggested that community-onset HCAP differs markedly from community-acquired pneumonia (CAP) and more closely resembles HAP. ${ }^{4-10}$ Since the microbiological spectrum of NCAP may encompass high-risk and potentially antibiotic-resistant pathogens, early clinical identification and an attempt to obtain microbiological documentation in suspected episodes of HAP and HCAP have been strongly recommended. ${ }^{1,5,7}$ However, the concept of HCAP has recently been revisited, ${ }^{11}$ and a systematic review and metaanalysis of HCAP studies have indicated that the currently accepted definition did not accurately identify subjects potentially infected by resistant pathogens and that mortality was primarily related to comorbidities rather than to infection with high-risk pathogens. ${ }^{12}$ Although studies have contrasted the epidemiological characteristics of HCAP and HAP, ${ }^{4-9,13}$ none have investigated the diagnostic challenge posed by NCAP in non-intubated patients.

We therefore conducted the present prospective study to (1) describe the clinical features and microbial etiologies of a series of non-intubated consecutive subjects suspected of NCAP, contrasting HAP and HCAP, and (2) assess the potential impact of performing microbiological samplings on diagnosis and management of subjects.

\section{Methods}

A complete section on subjects and methods is available as online supplementary information (see the supplementary materials at http://www.rcjournal.com).

\section{Subject Selection}

The study was prospectively conducted in 16 participating wards of Tenon Hospital, a 780-bed tertiary teaching hospital in Paris, France, between November 2005 and

\footnotetext{
Dr Verdet is affiliated with the Laboratoire de Bactériologie, Hôpital Tenon, AP-HP, Paris, France. Drs Prigent and Fartoukh are affiliated with the Service de Réanimation Médico-Chirurgicale, Hôpital Tenon, AP-HP, and Sorbonne Universités, UPMC Univ Paris 06, Paris, France.

Supplementary material related to this paper is available at http:// www.rcjournal.com.

This work was supported by a grant from la Société de Pneumologie de Langue Française. Dr Messika has disclosed a relationship with Basilea Pharmaceutica. The other authors have disclosed no conflicts of interest.

Correspondence: Muriel Fartoukh MD PhD, AP-HP, Hôpital Tenon, Service de Réanimation Médico-Chirurgicale, F-75970 Paris, France. E-mail: muriel.fartoukh@tnn.aphp.fr.
}

DOI: $10.4187 /$ respcare. 04143

\section{QUICK LOOK}

\section{Current knowledge}

Non-community-acquired pneumonia (NCAP) is differentiated into health care-associated pneumonia (HCAP), hospital-acquired pneumonia (HAP) developing $48 \mathrm{~h}$ after hospitalization, and ventilator-associated pneumonia developing during mechanical ventilation. The microbiological spectrum of NCAP can include antibiotic-resistant pathogens. Early clinical identification and microbiological documentation have been strongly recommended.

\section{What this paper contributes to our knowledge}

NCAP occurred most frequently in elderly subjects with severe underlying diseases and comorbid conditions, with HCAP accounting for one fifth of all episodes. The microbial spectrum of early-onset HAP and HCAP included community microorganisms and less frequently multidrug-resistant Gram-negative bacteria. Late-onset HAP is more likely to include multidrug-resistant organisms, similar to ventilator-associated pneumonia.

October 2006. The attending physicians of the participating wards notified one of the investigators when a patient was clinically suspected of having NCAP. All non-intubated adult subjects were included. NCAP episodes were classified into HAP or HCAP according to the current definitions. ${ }^{1}$ Pneumonia occurring $\geq 48 \mathrm{~h}$ after hospital admission and not considered incubating at the time of admission was classified as HAP and defined as earlyonset when occurring within the first $4 \mathrm{~d}$ of hospitalization. ${ }^{14}$ HCAP cases were pneumonia episodes diagnosed within the first $48 \mathrm{~h}$ of hospitalization in a subject with a known risk factor. ${ }^{1}$ Subjects having $\geq 1$ risk factor for HCAP but developing pneumonia $\geq 3 \mathrm{~d}$ of after the current hospitalization were considered as having HAP. For each subject, data recorded are detailed in the online supporting information. Antibiotics administered were classified as new, ongoing, or prior (see online supporting information).

\section{Study Protocol}

Clinical Diagnosis and Severity of Pneumonia. When a subject clinically suspected of having NCAP was referred to one of the investigators by the attending physician of the participating wards, the latter was asked to provide an estimate of the clinical probability of pneumonia on a $0-100 \%$ scale before obtaining microbiological samplings. This estimate was subsequently scored from 1 , 
or very low ( $0-20 \%$ probability estimate), to 5 , or very high (80-100\% estimate), and further dichotomized into a high-suspicion (score of 4 or 5) or a low-moderate-suspicion (score of 1-3) group. The clinical criteria of pneumonia were recorded, ${ }^{15}$ as well as the usual severity scores. ${ }^{16,17}$ The Clinical Pulmonary Infection Score (as described by Pugin et $\mathrm{al}^{18}$ and Singh et $\mathrm{al}^{19}$ ) was calculated a posteriori.

Microbiological Investigation. Whenever possible, microbiological investigations were performed in a sequential manner. Non-respiratory tract samplings (blood cultures and urinary soluble antigens) were first performed. Non-bronchoscopic (sputum) and bronchoscopic lower respiratory tract samplings (plugged telescopic catheter, tracheal aspirate, or bronchoalveolar lavage) were then obtained. Fiberoptic bronchoscopy (BF2B, Olympus, New Hyde Park, New York) was performed by one of the investigators, in the absence of contraindication. ${ }^{20}$ The usual thresholds for positivity of quantitative cultures were used. $^{21-24}$

Diagnosis of NCAP. Episodes of suspected pneumonia were categorized into confirmed (definite or probable diagnosis) and non-confirmed pneumonia (possible diagnosis or no pneumonia) (Fig. 1) (see online supporting information). Alternative diagnoses were considered in subjects with non-confirmed pneumonia.

Antimicrobial Treatment Administered for the Suspected Episode of Pneumonia and Outcome. Antimicrobial treatment administered for the suspected episode of pneumonia was left to the discretion of the attending physician. The appropriateness of antibiotics was independently assessed by the investigators. The vital status (death or discharged alive) was recorded for all subjects at hospital discharge and assessed after $30 \mathrm{~d}$ (see online supporting information).

\section{Statistical Analysis}

Demographics, clinical variables, and laboratory findings are reported as median (interquartile range) unless stated otherwise. Comparisons between confirmed and nonconfirmed episodes of pneumonia used the Mann-Whitney $\mathrm{U}$ test for quantitative variables and the chi-square test or Fisher exact test when required for nominal variables. Within-group changes were analyzed using the nonparametric signed rank test and the McNemar test for continuous and categorical variables, respectively. A $P$ value of $<.05$ was considered significant. Statistical analysis was performed with Stata 10.1 software (StataCorp, College Station, Texas).

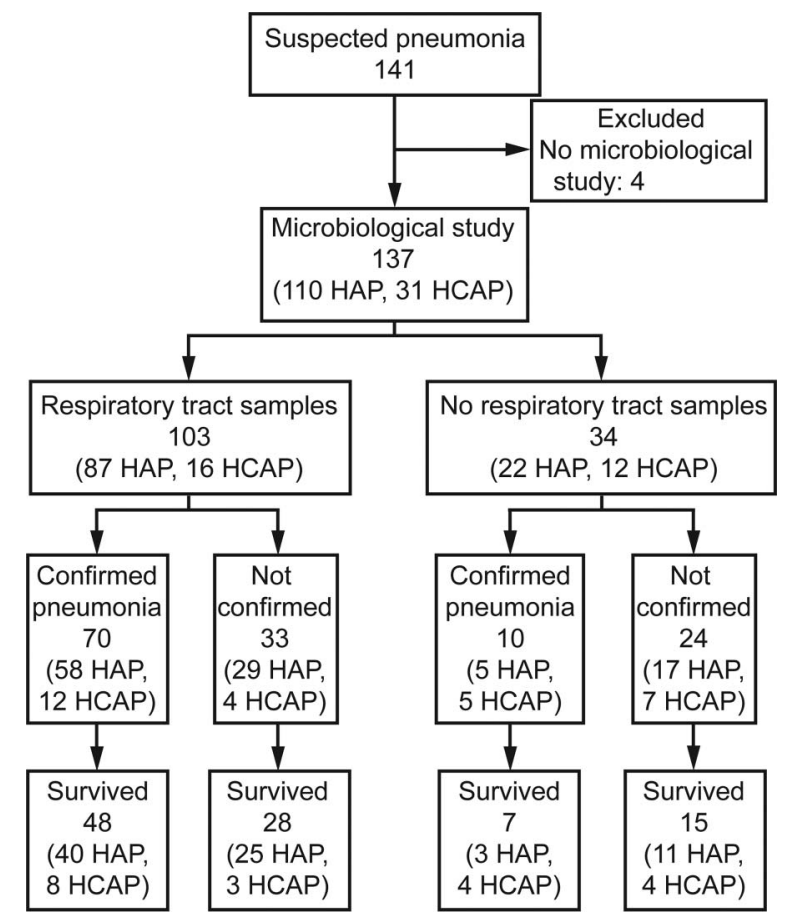

Fig. 1. Selection of the subjects. Among 141 suspected episodes of pneumonia, 137 were microbiologically investigated, achieving a $57 \%$ rate of diagnosis. There was no difference in subjects' survival, according to the collection of a respiratory tract specimen or the definite status of pneumonia (confirmed or not). HAP = hospital-acquired pneumonia; HCAP = health care-associated pneumonia.

\section{Ethical Considerations}

The ethical review board of the French Society of Intensive Care approved the study. Each subject or next-ofkin was given oral and written information. Informed consent was waived because the study was observational, and the procedures used followed the recommendations from the French Society of Intensive Care for standard clinical practice in patients with suspected NCAP.

\section{Results}

A complete results section is available as online supporting information.

During the 12-month study period, 13,909 consecutive patients were admitted to our hospital. Of those, 141 (1\%) subjects suspected of having NCAP were notified and were eligible to participate to the study (Fig. 1). There were 110 subjects suspected of having HAP (77 males, $66 \mathrm{y}$ ) and 31 suspected of having HCAP (19 males, $86 \mathrm{y}$ ). The duration of hospitalization before HAP was clinically suspected was $10 \mathrm{~d}$ (range 4-19 d; see Fig. E1 of the online supplementary information). Subjects suspected of having HCAP resided in a nursing home $(n=25$, including 1 subject 
receiving chronic dialysis), had hospital day care $(n=3)$, had been hospitalized in an acute care ward within the past 3 months $(n=2)$, and received chronic hemodialysis $(n=1)$. Mechanical ventilation, renal replacement therapy, and vasoactive drugs were administered to 14 (10\%), $10(7 \%)$, and 6 subjects (4\%) at inclusion, respectively.

\section{Clinical Diagnosis of Pneumonia}

Although most subjects had a high or very high clinical suspicion of pneumonia according to the clinical estimate of the attending physician (median estimate, interquartile range: $4,3-5)$, it should be noted that only 81 subjects $(57 \%)$ had at least 2 clinical criteria plus leukocytosis or leukopenia and a new chest radiograph infiltrate. The median CURB-65 score at inclusion was 2 points (range: 1-3) (Table 1).

The combination of at least 2 clinical criteria ${ }^{25,26}$ plus increased leukocytosis or leukopenia and new chest radiograph infiltrate was neither helpful to discriminate confirmed and non-confirmed episodes of pneumonia overall (46/80 [58\%] vs $33 / 57$ [58\%], $P=.95$ ) nor in the subgroup of subjects investigated with respiratory tract specimens (38/70 [54\%] vs $18 / 33$ [54\%], $P=.98)$. There were 59 suspected episodes of pneumonia $(42 \%)$ in which either new or ongoing antibiotics were administered at the time of pneumonia suspicion (new antibiotics, $n=21$; ongoing antibiotics, $n=44$ ) (Table 1).

\section{Microbiological Investigations}

At least one respiratory tract specimen was obtained in 103 subjects (73\%), mainly those suspected of HAP (87/110). A fiber-optic bronchoscopy was performed in 59 suspected episodes of pneumonia (42\%), more frequently in suspected HAP than HCAP (52/110 [47\%] vs 7/31 [23\%], $P=.01)$. Thus, suspected episodes of HAP were more often investigated with respiratory tract samples than suspected HCAP (87/110 [79\%] vs 16/31 [52\%], $P=.002)$ (Table 2). Of the 38 subjects in whom no respiratory tract sample was performed, 4 subjects (all suspected of having HCAP) had no microbiological investigation at all.

Seventy of the 103 subjects (68\%) in whom a respiratory tract specimen was obtained were adjudicated as having pneumonia (supplementary Fig. E2A), whereas only 10 of the 34 subjects (29\%) investigated by blood cultures or urinary antigen tests had confirmed pneumonia (supplementary Fig. E2B). Altogether, pneumonia was confirmed in 80 subjects $(57 \%)$, including $63(57 \%)$ of the 110 subjects with suspected HAP and $17(55 \%)$ of the 31 subjects with suspected HCAP $(P=.03)$ (Fig. 1). An alternative diagnosis was available for $32(52 \%)$ of the remaining 61 subjects, including atelectasis $(n=13)$, sepsis of non-pulmonary origin $(n=5)$, bronchitis/exacerbation of COPD $(n=4)$, pulmonary edema $(n=4)$, lung cancer $(n=4)$, hepatic encephalopathy $(n=1)$, and hypersensitivity pneumonitis $(n=1)$.

Of the 80 subjects having confirmed pneumonia (earlyonset HAP, $n=17$; late-onset HAP, $n=46$; HCAP, $n=17), 72$ had a microbiological documentation, including $57(79 \%)$ with HAP and $15(21 \%)$ with HCAP. More than 1 causative pathogen was identified in 20 confirmed pneumonia cases (28\%) (Fig. 2A), with a similar rate of polymicrobial pneumonia in $\mathrm{HAP}(16 / 57,28 \%)$ and HCAP $(4 / 15,27 \%)$.

\section{Pathogens Involved}

There were 59 suspected episodes of pneumonia (42\%) in which either new or ongoing antibiotics were administered at the time of pneumonia suspicion (new antibiotics, $n=21$; ongoing antibiotics, $n=44$ ) (Table 1).

There were 79 microorganisms isolated altogether. Multidrug-resistant aerobic Gram-negative bacilli, group III Enterobacteriacae $(n=28)$, and methicillin-resistant Staphylococcus aureus $(n=6)$ accounted for nearly one half of the isolated microorganisms $(n=34,43 \%)$ and were recovered in 31 episodes, including 26 of 63 documented HAP and 5 of 17 HCAP cases. Early-onset HAP and HCAP had a similar microbiological spectrum, with multidrugresistant aerobic Gram-negative bacilli and group III Enterobacteriacae accounting for one third of the microorganisms identified. Of note, methicillin-resistant $S$. aureus was most often recovered from subjects with HCAP. Conversely, late-onset HAP was caused by multidrug-resistant aerobic Gram-negative bacilli and group III Enterobacteriacae in half of the cases (Fig. 2B). There was a statistical trend for a higher rate of multidrug-resistant aerobic Gramnegative bacilli and group III Enterobacteriacae in lateonset HAP, as compared with early-onset HAP and HCAP (22/46, $48 \%$ vs $9 / 34,26 \%, P=.09)$.

\section{Appropriateness of Antimicrobial Treatment}

Of the 72 microbiologically documented episodes of pneumonia, $26(36 \%)$ received inappropriate empirical antimicrobial treatment (HAP 22/57 [39\%] vs HCAP 4/15 [27\%], $P=.4$ ). Despite a gradual increase of antibiotic appropriateness with time, $20 \%$ of the confirmed episodes were still inappropriately treated at $48 \mathrm{~h}$ (Fig. 3). Of note, empirical antimicrobial therapy was maintained for a median duration of $10 \mathrm{~d}$ (range: 7-13) in a majority of episodes $(25 / 32 ; 78 \%)$ in which respiratory tract specimen cultures were negative, despite an alternative diagnosis in $56 \%$ of the cases (14 of 25 subjects).

\section{Outcomes of Subjects}

Length of hospital stay averaged $26 \mathrm{~d}$ (range 15-38 d). Forty subjects were admitted to the ICU, 13 (33\%) of 


\section{Diagnosis of Non-Community-AcQuired Pneumonia}

Table 1. Demographics and Clinical Variables at Inclusion

\begin{tabular}{|c|c|c|c|c|}
\hline & $\begin{array}{l}\text { Clinically Suspected Pneumonia } \\
\qquad(n=141)\end{array}$ & $\begin{array}{l}\text { Clinically Suspected } \\
\text { HAP }(n=110)\end{array}$ & $\begin{array}{l}\text { Clinically Suspected } \\
\operatorname{HCAP}(n=31)\end{array}$ & $P$ \\
\hline Age, median (IQR) y & $68(55-83)$ & $67(54-81)$ & $86(64-93)$ & $<.001$ \\
\hline Male sex, $n(\%)$ & $96(68)$ & $77(70)$ & $19(61)$ & .52 \\
\hline Performance status $\geq 2, n(\%)^{*}$ & $92(67)$ & $65(59)$ & $27(93)$ & .009 \\
\hline MacCabe index $\geq 2, n(\%)$ & $130(92)$ & $99(90)$ & $31(100)$ & .15 \\
\hline $\begin{array}{l}\text { Duration of hospitalization before inclusion, } \\
\text { median (IQR) d }\end{array}$ & $7(3-15)$ & $10(4-19)$ & & \\
\hline \multicolumn{5}{|l|}{ Comorbid conditions, $n(\%)$} \\
\hline Pulmonary & $25(18)$ & 20 & 5 & $>.99$ \\
\hline Cardiac & $66(47)$ & 48 & 18 & .22 \\
\hline Renal & $23(16)$ & 18 & 5 & .88 \\
\hline Neurologic & $47(33)$ & 34 & 13 & .28 \\
\hline Ear, nose, and throat & $13(9)$ & 10 & 3 & .92 \\
\hline Liver & $17(12)$ & 14 & 3 & .76 \\
\hline Diabetes mellitus & $20(14)$ & 18 & 2 & .25 \\
\hline HIV/AIDS & $8(6)$ & 7 & 1 & .69 \\
\hline Immunosuppression & $69(49)$ & 58 & 11 & .11 \\
\hline Antibiotic exposure before inclusion, $n(\%) \dagger$ & $72(51)$ & $58(53)$ & $14(45)$ & .46 \\
\hline During the past 3 months & $43(30)$ & $33(30)$ & $10(32)$ & .81 \\
\hline Ongoing & $44(31)$ & $36(33)$ & $8(26)$ & .46 \\
\hline New & $21(15)$ & $13(12)$ & $8(26)$ & .053 \\
\hline Prior & $28(20)$ & $25(23)$ & $3(10)$ & .11 \\
\hline \multicolumn{5}{|l|}{ Clinical criteria at inclusion, $n(\%)$} \\
\hline Cough & $76(54)$ & $57(52)$ & $19(63)$ & .42 \\
\hline Expectoration & $53(38)$ & $44(40)$ & $9(29)$ & .37 \\
\hline Rales & $119(84)$ & $92(84)$ & $27(87)$ & .23 \\
\hline Tachypnea $>25$ counts $/ \mathrm{min}$ & $72(51)$ & $47(43)$ & $25(81)$ & .001 \\
\hline Temperature $>37.8^{\circ} \mathrm{C}$ & $93(66)$ & $73(66)$ & $20(65)$ & .83 \\
\hline Oxygen saturation $<92 \%$ & $105(74)$ & $78(71)$ & $27(87)$ & .18 \\
\hline Chest pain & $16(11)$ & $15(14)$ & $1(3)$ & .23 \\
\hline \multicolumn{5}{|l|}{ Blood leukocyte count, $n(\%)$} \\
\hline$>10,000 \mathrm{~mm}^{3}$ & $76(54)$ & $57(52)$ & $19(61)$ & .35 \\
\hline$<4,000 \mathrm{~mm}^{3}$ & $11(8)$ & $9(8)$ & $2(6)$ & .75 \\
\hline New chest radiograph infiltrates, $n(\%)$ & $128(91)$ & $99(90)$ & $29(94)$ & .09 \\
\hline $\begin{array}{c}\geq 2 \text { clinical criteria plus leukocytosis or leukopenia } \\
\text { and a new chest radiograph infiltrate, } n(\%)\end{array}$ & $81(57)$ & $59(54)$ & $22(71)$ & .09 \\
\hline $\begin{array}{l}\text { Clinical estimate of pneumonia at inclusion, median } \\
\text { (IQR) score } \$\end{array}$ & $4(3-5)$ & $4(3-5)$ & $4(4-5)$ & .49 \\
\hline CPIS at inclusion, median (IQR) score§ & $5(4-7)$ & $5(4-7)$ & $6(5-6)$ & .49 \\
\hline CURB-65 score at inclusion, median (IQR) score & $2(1-3)$ & $2(1-3)$ & $3(2-4)$ & .001 \\
\hline Mechanical ventilation at inclusion, $n(\%)$ & $14(10)$ & $12(11)$ & $2(6)$ & .73 \\
\hline Renal replacement at inclusion, $n(\%)$ & $10(7)$ & $6(5)$ & $4(13)$ & .23 \\
\hline Vasoactive drugs at inclusion, $n(\%)$ & $6(4)$ & $5(5)$ & $1(3)$ & $>.99$ \\
\hline \multicolumn{5}{|c|}{$\begin{array}{l}\text { A } P \text { value of }<.05 \text { indicates a statistical difference between suspected episodes of hospital-acquired pneumonia and health care-associated pneumonia. } \\
\text { * Performance status was estimated according to the Eastern Cooperative Oncology Group Scale as follows: } 0 \text {, fully active; } 1 \text {, restricted in physically strenuous activity; } 2 \text {, ambulatory and capable of } \\
\text { all self-care but unable to carry out any work activities; } 3 \text {, confined to bed or chair more than } 50 \% \text { of waking hours; } 4 \text {, bedridden. } \\
\dagger \text { Antibiotics were classified as new if recently introduced }(<72 \mathrm{~h} \text { ), ongoing when they were introduced } \geq 72 \mathrm{~h} \text { prior to inclusion, and prior when they had been given within the preceding } 15 \text { days } \\
\text { for }>24 \mathrm{~h} \text { and stopped for at least } 72 \mathrm{~h} \text { before inclusion. The prior antibiotic exposure within the past } 3 \text { months (ie, any antibiotic for any duration during the past } 3 \text { months) was also assessed. } \\
\ddagger \text { Clinical estimate of pneumonia was provided by the attending physician on a } 0-100 \% \text { scale and categorized as (1) very low when the probability was scored }<20 \% \text {, (2) low when scored between } \\
20 \text { and } 40 \%, \text { (3) moderate when scored between } 40 \text { and } 60 \%,(4) \text { high between } 60 \text { and } 80 \% \text {, and (5) very high when scored between } 80 \text { and } 100 \% \text {. }\end{array}$} \\
\hline
\end{tabular}




\section{Diagnosis of Non-Community-AcquiRed Pneumonia}

Table 2. Microbiological Investigation Actually Performed According to the Clinical Suspicion of Pneumonia

\begin{tabular}{|c|c|c|c|c|c|c|c|c|c|}
\hline & \multicolumn{3}{|c|}{$\begin{array}{l}\text { Clinically Suspected Pneumonia } \\
\qquad(n=141)\end{array}$} & \multicolumn{3}{|c|}{$\begin{array}{l}\text { Clinically Suspected HAP } \\
\qquad(n=110)\end{array}$} & \multicolumn{3}{|c|}{$\begin{array}{l}\text { Clinically Suspected HCAP } \\
\qquad(n=31)\end{array}$} \\
\hline & All $n(\%)$ & $\begin{array}{c}\text { Confirmed } \\
n\end{array}$ & $\begin{array}{c}\text { Non- } \\
\text { Confirmed } \\
n\end{array}$ & All $n(\%)$ & $\begin{array}{c}\text { Confirmed } \\
n\end{array}$ & $\begin{array}{c}\text { Non- } \\
\text { Confirmed } \\
n\end{array}$ & All $n(\%)$ & $\begin{array}{c}\text { Confirmed } \\
n\end{array}$ & $\begin{array}{c}\text { Non- } \\
\text { Confirmed } \\
n\end{array}$ \\
\hline Microbiological investigation & $137(97)$ & 80 & 57 & $109(99)$ & 63 & 46 & $28(90)$ & 17 & 11 \\
\hline Respiratory tract specimens & $103(73)$ & 70 & 33 & $87(79)$ & 58 & 29 & $16(52)$ & 12 & 4 \\
\hline $\begin{array}{l}\text { Non-bronchoscopically guided } \\
\text { Sputum }\end{array}$ & $51(36)$ & 35 & 16 & $43(39)$ & 28 & 15 & $8(26)$ & 7 & 1 \\
\hline Bronchoscopically guided & $59(42)$ & 38 & 21 & $52(47)$ & 34 & 18 & $7(23)$ & 4 & 3 \\
\hline PTC & $56(40)$ & 36 & 20 & $50(45)$ & 32 & 18 & $6(19)$ & 4 & 2 \\
\hline $\mathrm{TA}$ & $43(30)$ & 28 & 15 & $36(33)$ & 24 & 12 & $7(23)$ & 4 & 3 \\
\hline BAL & $6(4)$ & 4 & 2 & $6(5)$ & 4 & 2 & 0 & 0 & 0 \\
\hline Non-respiratory tract specimens alone & $34(24)$ & 10 & 24 & $22(20)$ & 5 & 17 & $12(39)$ & 5 & 7 \\
\hline Blood culture alone & $11(8)$ & 2 & 9 & $6(5)$ & 1 & 5 & $5(16)$ & 1 & 4 \\
\hline Blood culture or urinary antigens & $23(16)$ & 8 & 15 & $16(15)$ & 4 & 12 & $7(23)$ & 4 & 3 \\
\hline No microbiological investigation & $4(3)$ & NA & NA & $1(1)$ & NA & NA & $3(10)$ & NA & NA \\
\hline $\begin{array}{l}\text { Results are expressed as } n(\%) . \text { Microbiological inve } \\
\text { HAP }=\text { hospital-acquired pneumonia } \\
\text { HCAP = health care-associated pneumonia } \\
\text { PTC }=\text { plugged telescopic catheter } \\
\text { TA }=\text { tracheal aspirate } \\
\text { BAL = bronchoalveolar lavage } \\
\text { NA = not applicable }\end{array}$ & estigation was & erformed in $137 \mathrm{~s}$ & ubjects clinically & suspected of pr & heumonia. & & & & \\
\hline
\end{tabular}

whom died. Overall, 39 subjects (28\%) died in the hospital, with a similar proportion of deaths among those with suspected HAP or HCAP (30/110 [27\%] vs 9/31 [29\%], $P=.85$ ). All in-hospital deaths outside of the ICU occurred after do-not-resuscitate orders. The proportion of hospital deaths was similar between subjects infected with multidrug-resistant aerobic Gram-negative bacilli and group III Enterobacteriacae and their counterparts $(8 / 24$ [33\%] vs $14 / 48$ [29\%], $P=.7$ ). Of the 102 subjects discharged alive, 32 (23\%) died during the post-discharge follow up period, which averaged $128 \mathrm{~d}$. Of note, postdischarge deaths were twice as common with suspected HCAP than with suspected HAP (12/22 [55\%] vs 20/80 [25\%], $P=.008$ ) (Table 3).

\section{Discussion}

In this prospective observational study, we describe the clinical presentation and microbial spectrum of NCAP in a series of unselected non-mechanically ventilated subjects, hospitalized in a tertiary teaching hospital in France during a 1-y period. A majority had HAP, and less than one fourth (21\%) had HCAP. Most subjects were elderly with underlying diseases and comorbid conditions and had been exposed to antibiotics before pneumonia was clinically suspected. The usual clinical criteria were of little help for diagnosing pneumonia, since almost $50 \%$ of subjects suspected of pneumonia were actually adjudicated as not hav- ing pneumonia. Similar rates of suspected HAP and HCAP were microbiologically confirmed, with a broad microbial spectrum including $40 \%$ of multidrug-resistant pathogens. Our results suggest that microbiological samplings, especially respiratory tract specimens, should be obtained whenever possible to select and adjust antimicrobial treatment in this context.

The incidence of NCAP averaged 1 per 1,000 admissions in our series, similarly to previous series of HAP that reported an incidence ranging from 1 to 10 per 1,000 hospital admissions, depending on the subjects studied, the case definition used, and the available information at hospital admission. ${ }^{3,5,7,8}$ The clinical diagnosis of NCAP usually relies on a combination of various criteria, including the presence of a new radiographic infiltrate associated with fever and several clinical signs among dyspnea, cough, purulent sputum, pleuritic chest pain, and leukocytosis or leukopenia and sometimes hypoxemia, in patients with specific risk factors or hospitalized for $>48-72$ h. ${ }^{3,5,7,8}$ However, these criteria, either isolated or combined, are of limited diagnostic value. ${ }^{9,27}$ In our series, $<60 \%$ of subjects fulfilled the combination of at least 2 clinical signs suggestive of pneumonia associated with leukocytosis or leukopenia and a new pulmonary infiltrate at the time of pneumonia suspicion. Moreover, the latter criteria did not perform better than a subjective clinical estimate alone for diagnosing pneumonia. The use of a simple tool, the modified Clinical Pulmonary Infection Score, might be helpful 

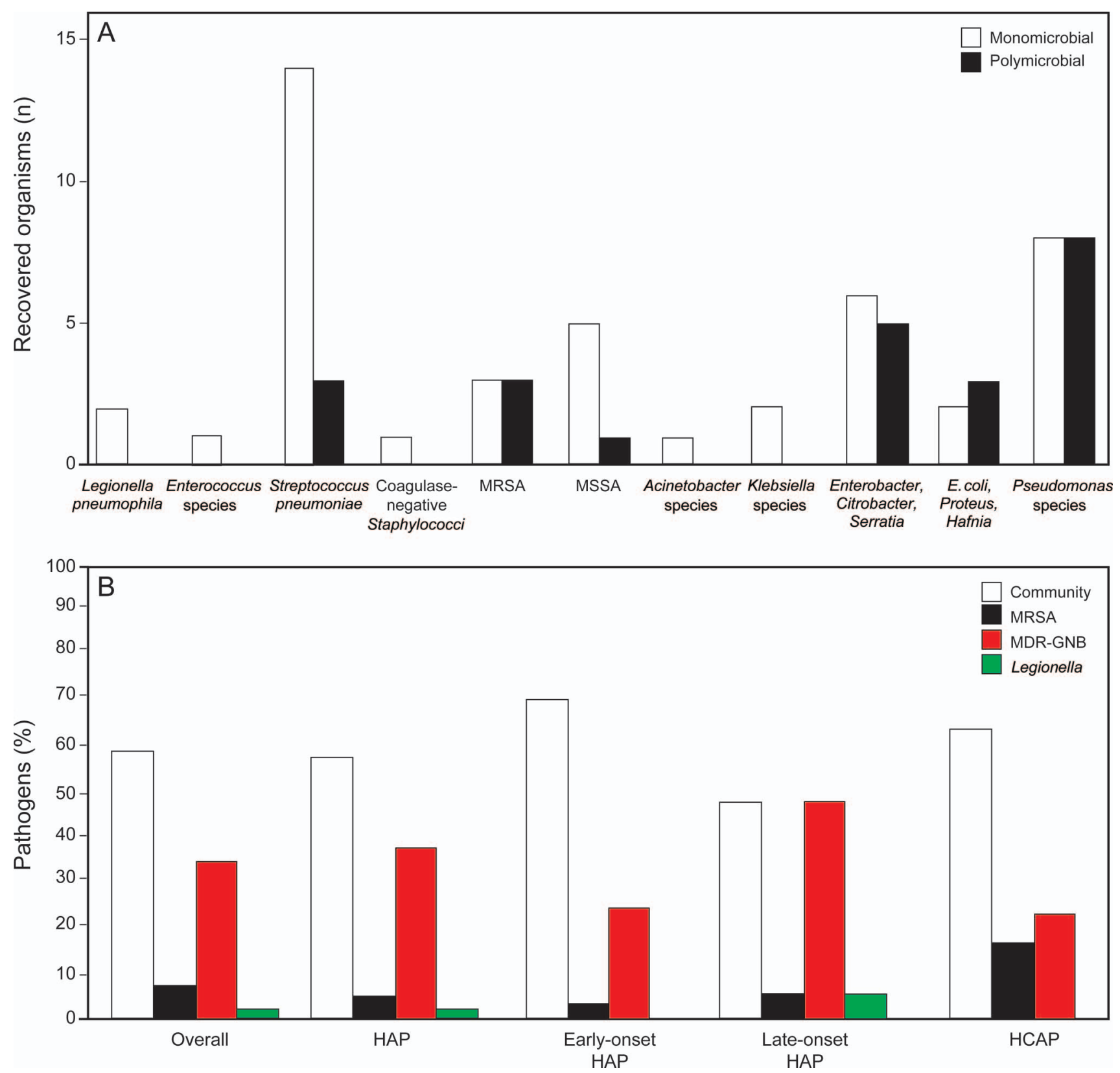

Fig. 2. Microorganisms recovered in episodes of confirmed non-community-acquired pneumonia. Pneumonia was diagnosed in 80 subjects and microbiologically documented in 72 (A). There were 79 microorganisms isolated altogether, multidrug-resistant aerobic Gram-negative bacilli (MDR-GNB), group III Enterobacteriacae, and methicillin-resistant Staphylococcus aureus (MRSA) accounting for nearly half of the microorganisms $(n=34,43 \%)$. More than one causative pathogen was identified in 20 confirmed pneumonias (25\%). Microbiological workup encompassed non-respiratory (blood cultures and urinary soluble antigens tests) and respiratory tract samplings (sputum and bronchoscopic samplings (plugged telescopic catheter, tracheal aspirate, or bronchoalveolar lavage); B: multidrug-resistant aerobic Gram-negative bacilli, group III Enterobacteriacae, and to a lesser degree methicillin-resistant $S$. aureus accounted for nearly half of the microorganisms isolated in the 72 episodes of confirmed pneumonia. HAP = hospital-acquired pneumonia; HCAP = health care-associated pneumonia.

for discriminating confirmed and non-confirmed episodes. This clinical score has been widely used and validated in the ICU, ${ }^{18,28}$ but its performance has rarely been assessed in hospitalized non-mechanically ventilated patients. ${ }^{29}$

In our series, a microbiological diagnosis was obtained in $70 \%$ of the episodes investigated with respiratory tract specimens (bronchoscopically guided or not), as compared with a $30 \%$ microbiological diagnosis rate in the subjects who were not investigated with respiratory tract specimens. A microbiological diagnosis was obtained in 36$52 \%$ of subjects in a previous series of NCAP, when using noninvasive diagnostic tools..$^{4,6,8-10}$ Although our study was 


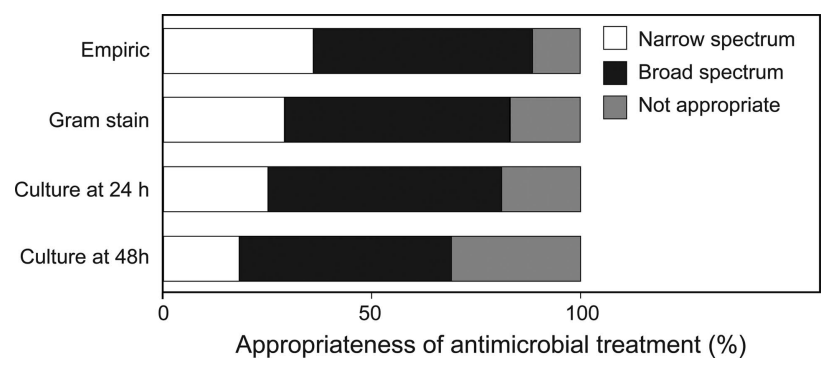

Fig. 3. Appropriateness of antimicrobial treatment administered at each step of the procedure of diagnosis of pneumonia. Broad antimicrobial treatment encompassed all of the microorganisms recovered from blood cultures or respiratory tract specimen cultures at or above the respective thresholds. Narrow antimicrobial treatment was defined as appropriate treatment with regard to the speciation and the antibiotic susceptibility profile.

Table 3. Outcomes

\begin{tabular}{|c|c|c|c|}
\hline & $\begin{array}{l}\text { Clinically } \\
\text { Suspected } \\
\text { Pneumonia }\end{array}$ & $\begin{array}{l}\text { Clinically } \\
\text { Suspected } \\
\text { HAP }\end{array}$ & $\begin{array}{l}\text { Clinically } \\
\text { Suspected } \\
\text { HCAP }\end{array}$ \\
\hline In hospital, $n$ & 141 & 110 & 31 \\
\hline \multicolumn{4}{|l|}{$\begin{array}{l}\text { Length of hospital stay, } \\
\text { median (IQR) d }\end{array}$} \\
\hline From hospital admission & $26(15-38)$ & $30(19-44)$ & $11(7-18)$ \\
\hline From inclusion & $15(8-27)$ & $16(8-30)$ & $11(7-22)$ \\
\hline ICU admission, $n(\%)$ & $40(28)$ & $33(30)$ & $7(23)$ \\
\hline Deaths, $n(\%)$ & $39(28)$ & $30(27)$ & $9(29)$ \\
\hline After hospital discharge, $n$ & 102 & 80 & 22 \\
\hline $\begin{array}{l}\text { Follow-up duration, } \\
\text { median (IQR) d }\end{array}$ & $105(33-193)$ & $106(42-197)$ & $64(15-177)$ \\
\hline Deaths, $n(\%)$ & $32(32)$ & $20(25)$ & $12(55)$ \\
\hline \multicolumn{4}{|c|}{$\begin{array}{l}\text { HAP }=\text { hospital-acquired pneumonia } \\
\text { HCAP = health care-associated pneumonia } \\
\text { IQR = interquartile range }\end{array}$} \\
\hline
\end{tabular}

not designed to compare 2 strategies of microbiological investigation (ie, respiratory versus non-respiratory tract investigation), our findings would suggest obtaining respiratory tract specimens whenever possible. This approach is further supported by the fact that almost $40 \%$ of the microbiologically documented episodes were not initially treated with appropriate antibiotics. Moreover, an alternative diagnosis was obtained in more than half of the subjects suspected of pneumonia and in whom the microbiological investigation was eventually negative, again emphasizing the complexity of the clinical diagnosis and the need for performing microbiological investigation in this context. ${ }^{1,30}$ It is worth pointing out that suspected HAP cases were more often investigated than HCAP, because of the physicians' reluctance to perform fiber-optic bronchoscopy and invasive samplings in older, more fragile and comorbid subjects.
Similarly to the approach taken in ventilator-associated pneumonia, we prospectively separated early- and lateonset HAP, according to whether pneumonia was diagnosed within $4 \mathrm{~d}$ or later after hospital admission. Indeed, the distribution of the etiologic pathogens differed with the time to pneumonia occurrence, with a higher rate of multidrug-resistant aerobic Gram-negative bacilli and group III Enterobacteriacae in late-onset HAP, as compared with early-onset HAP or HCAP episodes. There was a trend toward more methicillin-resistant $S$. aureus-related infections in HCAP subjects, as compared with HAP. However, available data on the bacterial epidemiology of HCAP are conflicting and may vary according to geographical areas. For instance, in a Spanish multicenter case-control study, Polverino et $\mathrm{al}^{29}$ found a similar microbial spectrum in HCAP and CAP. Conversely, Giannella et $\mathrm{al}^{27}$ reported findings comparable with ours. In our series, $20 \%$ of subjects with documented episodes of pneumonia were still receiving inappropriate antibiotics after $48 \mathrm{~h}$ of therapy. Altogether, these observations would favor the empirical use of broad-spectrum antibiotics, especially in late-onset HAP and in those at risk of multidrug-resistant pathogens, which should be associated with a thorough microbial investigation in order to allow de-escalation of empiric therapy.

The microbial spectrum of NCAP has also been shown to include both Streptococcus pneumoniae and Legionella pneumophila in addition to nosocomial pathogens, in proportions that are difficult to assess because of the limited available information about diagnostic procedures used in most reported series and the generally infrequent use of invasive diagnostic procedures. ${ }^{7,9}$ In our series, community microorganisms accounted for $50 \%$ of all of the microorganisms isolated. Urinary antigen tests were positive for S. pneumoniae and L. pneumophila in 8 and $2 \%$ of the cases, respectively, whereas blood cultures were positive in $8 \%$, as previously reported. ${ }^{9}$ Urinary antigen tests and blood cultures may thus be useful in the diagnostic workup of HAP as well as sputum cultures, although their values remain controversial because of the risk of contamination by the oropharyngeal flora. ${ }^{9}$

In 2005, the American Thoracic Society/Infectious Diseases Society of America guidelines suggested that HCAP should be considered as a new category of communityonset pneumonia occurring in patients residing in longterm care facilities and in individuals recently hospitalized or who had recent contact with the health-care system, although few studies were actually available to support this proposal.7,31 Some observational studies from both Europe and the United States suggested that communityacquired, hospital-acquired, and health care-associated pneumonia should be considered as 3 distinct epidemiologic clinical and microbial entities, $, 5,10,31$ since both their microbial spectrum and outcome may widely differ. How- 


\section{Diagnosis of Non-Community-Acquired Pneumonia}

ever, more recent studies, especially from European investigators, suggest that the proportion of subjects with HCAP infected by multidrug-resistant microorganisms was lower than previously reported, and a revision of the concept of HCAP has been suggested. ${ }^{11,32,33}$ A recent series in Ja$\operatorname{pan}^{34}$ and a systematic review and meta-analysis pointed out that the proposed criteria for HCAP did not accurately identify subjects infected with resistant pathogens and that mortality was primarily related to comorbidities rather than to high-risk pathogens. ${ }^{12,35,36}$ It is noteworthy that in our series, in-hospital mortality reached $30 \%$ in both HAP and HCAP episodes, whereas post-discharge deaths were twice as common in HCAP. These findings concur with others $^{35,36}$ and point to a major influence of age and associated comorbid conditions on the outcome of patients with HCAP. Our findings confirm that HCAP should be considered apart from HAP.

Despite its prospective design, our study has several limitations. Because inclusion was based on physicians' notifications, the number of subjects suspected of having pneumonia might have been underestimated. In a 1-day point prevalence study performed in the participating wards, we found that $20 \%$ of the hospitalized subjects with pneumonia had not been notified, thus not included. Moreover, the subjects admitted to the hospital with a diagnosis of HCAP might have been selected and referred to the hospital on the basis of severity criteria, thus not reflecting the overall epidemiology of HCAP. Second, this was a singlecenter study, and our findings should be confirmed in a multi-center study.

\section{Conclusion}

To summarize, NCAP mostly occurs in elderly patients with severe underlying diseases and comorbid conditions, with HCAP accounting for one fifth of all episodes. Making an accurate clinical diagnosis remains a challenge, and a rigorous microbiological investigation is mandatory to improve diagnosis performance. The usefulness of the Clinical Pulmonary Infection Score should be investigated in that setting. The microbial spectrum of early-onset HAP and HCAP may encompass community microorganisms and to a lesser degree multidrug-resistant Gram-negative bacteria and group III Enterobacteriacae. Conversely, lateonset HAP is at high risk of infection with multidrugresistant microorganisms, similarly to ventilator-associated pneumonia. In our environment, methicillin-resistant $S$. $a u$ reus was rare in subjects with HAP, whereas it was an important pathogen in those with HCAP. These findings highlight the variable epidemiological profile of HAP and HCAP and the need to develop simple diagnostic tools for selecting patients in whom microbiological investigations should be performed, to confirm pneumonia as well as to reduce excessive broad-spectrum initial empirical cover- age and avoid unnecessary continuation of antimicrobial treatment.

\section{REFERENCES}

1. American Thoracic Society, Infectious Diseases Society of America. Guidelines for the management of adults with hospital-acquired, ventilator-associated, and healthcare-associated pneumonia. American journal of respiratory and critical care medicine 2005;171(4): 388-416.

2. Chastre J, Fagon JY. Ventilator-associated pneumonia. American journal of respiratory and critical care medicine 2002;165(7):867903.

3. Magill SS, Edwards JR, Bamberg W, Beldavs ZG, Dumyati G, Kainer MA, et al. Multistate point-prevalence survey of health care-associated infections. N Engl J Med 2014;370(13):1198-1208.

4. Bartlett JG, O'Keefe P, Tally FP, Louie TJ, Gorbach SL. Bacteriology of hospital-acquired pneumonia. Arch Intern Med 1986;146(5): 868-871.

5. Carratalà J, Mykietiuk A, Fernández-Sabé N, Suárez C, Dorca J, Verdaguer R, et al. Health care-associated pneumonia requiring hospital admission: epidemiology, antibiotic therapy, and clinical outcomes. Arch Intern Med 2007;167(13):1393-1399.

6. Greenaway CA, Embil J, Orr PH, McLeod J, Dyck B, Nicolle LE. Nosocomial pneumonia on general medical and surgical wards in a tertiary-care hospital. Infect Control Hosp Epidemiol 1997;18(11): 749-756.

7. Kollef MH, Shorr A, Tabak YP, Gupta V, Liu LZ, Johannes RS. Epidemiology and outcomes of health-care-associated pneumonia: results from a large US database of culture-positive pneumonia. Chest 2005;128(6):3854-3862.

8. Schleupner CJ, Cobb DK. A study of the etiologies and treatment of nosocomial pneumonia in a community-based teaching hospital. Infect Control Hosp Epidemiol 1992;13(9):515-525.

9. Sopena N, Sabrià M, Neunos 2000 Study Group. Multicenter study of hospital-acquired pneumonia in non-ICU patients. Chest 2005; 127(1):213-219.

10. Venditti M, Falcone M, Corrao S, Licata G, Serra P. Outcomes of patients hospitalized with community-acquired, health care-associated, and hospital-acquired pneumonia. Ann Intern Med 2009;150(1): 19-26.

11. Ewig S, Welte T, Chastre J, Torres A. Rethinking the concepts of community-acquired and health-care-associated pneumonia. Lancet 2010;10(4):279-287.

12. Chalmers JD, Rother C, Salih W, Ewig S. Healthcare-associated pneumonia does not accurately identify potentially resistant pathogens: a systematic review and meta-analysis. Clin Infect Dis 2014; 58(3):330-339.

13. Chalmers JD, Taylor JK, Singanayagam A, Fleming GB, Akram AR, Mandal P, et al. Epidemiology, antibiotic therapy, and clinical outcomes in health care-associated pneumonia: a UK cohort study. Clin Infect Dis 2011;53(2):107-113.

14. Trouillet JL, Chastre J, Vuagnat A, Joly-Guillou ML, Combaux D, Dombret MC, Gibert C. Ventilator-associated pneumonia caused by potentially drug-resistant bacteria. American journal of respiratory and critical care medicine 1998;157(2):531-539.

15. McCabe WJ, Jackson GG. Gram-negative bacteremia. II. Clinical, laboratory and therapeutic observations. Arch Intern Med 1962; 110(6):856-864. doi: 10.1001/archinte.1962.03620240038007

16. Lim WS, van der Eerden MM, Laing R, Boersma WG, Karalus N, Town GI, et al. Defining community acquired pneumonia severity on presentation to hospital: an international derivation and validation study. Thorax 2003;58(5):377-382. 


\section{Diagnosis of Non-Community-AcQuired PNeumonia}

17. Le Gall JR, Klar J, Lemeshow S, Saulnier F, Alberti C, Artigas A, Teres D. The logistic organ dysfunction system: a new way to assess organ dysfunction in the intensive care unit: ICU scoring group. JAMA 1996;276(10):802-810.

18. Pugin J, Auckenthaler R, Mili N, Janssens JP, Lew PD, Suter PM. Diagnosis of ventilator-associated pneumonia by bacteriologic analysis of bronchoscopic and nonbronchoscopic "blind" bronchoalveolar lavage fluid. Am Rev Respir Dis 1991;143(5 Pt 1):1121-1129.

19. Singh N, Rogers P, Atwood CW, Wagener MM, Yu VL. Shortcourse empiric antibiotic therapy for patients with pulmonary infiltrates in the intensive care unit: a proposed solution for indiscriminate antibiotic prescription. Am J Respir Crit Care Med 2000;162(2 Pt 1):505-511.

20. British Thoracic Society Bronchoscopy Guidelines Committee, a Subcommittee of Standards of Care Committee of British Thoracic Society. British Thoracic Society guidelines on diagnostic flexible bronchoscopy. Thorax 2001;56(Suppl 1):i1-i21.

21. Fàbregas N, Ewig S, Torres A, El-Ebiary M, Ramirez J, de La Bellacasa JP, et al. Clinical diagnosis of ventilator associated pneumonia revisited: comparative validation using immediate post-mortem lung biopsies. Thorax 1999;54(10):867-873 .

22. Marquette CH, Herengt F, Saulnier F, Nevierre R, Mathieu D, Courcol $\mathrm{R}$, Ramon P. Protected specimen brush in the assessment of ventilator-associated pneumonia: selection of a certain lung segment for bronchoscopic sampling is unnecessary. Chest 1993;103(1):243-247.

23. Meduri GU, Chastre J. The standardization of bronchoscopic techniques for ventilator-associated pneumonia. Chest 1992;102(5 Suppl 1):557S-564S

24. Pham LH, Brun-Buisson C, Legrand P, Rauss A, Verra F, Brochard L, Lemaire F. Diagnosis of nosocomial pneumonia in mechanically ventilated patients: comparison of a plugged telescoping catheter with the protected specimen brush. Am Rev Respir Dis 1991;143(5 Pt 1):1055-1061.

25. Chidiac C. [Management of lower respiratory tract infections in immunocompetent adults (community-acquired pneumonia and acute exacerbation of chronic obstructive pulmonary disease): the challenge of a new consensus conference]. Med Mal Infect 2006;36(11): 535-537. Article in French.

26. Mandell LA, Wunderink RG, Anzueto A, Bartlett JG, Campbell GD, Dean NC, et al. Infectious Diseases Society of America/American Thoracic Society consensus guidelines on the management of com- munity-acquired pneumonia in adults. Clin Infect Dis 2007;44(Suppl 2):S27-S72

27. Giannella M, Pinilla B, Capdevila JA, Martínez Alarcón J, Muñoz P, López Álvarez J, et al. Pneumonia treated in the internal medicine department: focus on healthcare-associated pneumonia. Clin Microbiol Infect 2012;18(8):786-794.

28. Fartoukh M, Maitre B, Honoré S, Cerf C, Zahar JR, Brun-Buisson C. Diagnosing pneumonia during mechanical ventilation: the clinical pulmonary infection score revisited. Am J Respir Crit Care Med 2003;168(2):173-179.

29. Polverino E, Torres A, Menendez R, Cillóniz C, Valles JM, Capelastegui A, et al. Microbial aetiology of healthcare associated pneumonia in Spain: a prospective, multicentre, case-control study. Tho$\operatorname{rax} 2013 ; 68(11): 1007-1014$.

30. Lacroix G, Prunet B, Bordes J, Cabon-Asencio N, Asencio Y, Gaillard T, et al. Evaluation of early mini-bronchoalveolar lavage in the diagnosis of health care-associated pneumonia: a prospective study. Crit Care 2013;17(1):R24.

31. Micek ST, Kollef KE, Reichley RM, Roubinian N, Kollef MH. Health care-associated pneumonia and community-acquired pneumonia: a single-center experience. Antimicrob Agents Chemother 2007;51(10):3568-3573.

32. Aliberti S, Di Pasquale M, Zanaboni AM, Cosentini R, Brambilla AM, Seghezzi S, et al. Stratifying risk factors for multidrug-resistant pathogens in hospitalized patients coming from the community with pneumonia. Clin Infect Dis 2012;54(4):470-478.

33. Aliberti S, Cilloniz C, Chalmers JD, Zanaboni AM, Cosentini R, Tarsia P, et al. Multidrug-resistant pathogens in hospitalised patients coming from the community with pneumonia: a European perspective. Thorax 2013;68(11):997-999.

34. Shindo Y, Ito R, Kobayashi D, Ando M, Ichikawa M, Shiraki A, et al. Risk factors for drug-resistant pathogens in community-acquired and healthcare-associated pneumonia. Am J Respir Crit Care Med 2013;188(8):985-995

35. Kett DH, Cano E, Quartin AA, Mangino JE, Zervos MJ, Peyrani P, et al. Implementation of guidelines for management of possible multidrug-resistant pneumonia in intensive care: an observational, multicentre cohort study. Lancet 2011;11(3):181-189.

36. Chung DR, Song JH, Kim SH, Thamlikitkul V, Huang SG, Wang H, et al. High prevalence of multidrug-resistant nonfermenters in hospital-acquired pneumonia in Asia. Am J Respir Crit Care Med 2011; 184(12):1409-1417. 